\title{
Numerical Analysis on Characteristics of Reduction Process within a Pre-Reduction Rotary Kiln
}

\author{
Chenghong Liu ${ }^{1}$, Xueyong Ding ${ }^{1, *}$, Hegong Liu ${ }^{1}$, Xinlin Yan ${ }^{2}$, Chao Dong ${ }^{3}$ and Jia Wang ${ }^{4}$ \\ 1 School of Metallurgy, Northeastern University, Shenyang 110819, China; hcl123love@126.com (C.L.); \\ liu306827@163.com (H.L.) \\ 2 Institute of Solid State Physics, Vienna University of Technology, Wiedner Hauptstr. 8-10, \\ 1040 Vienna, Austria; yan@ifp.tuwien.ac.at \\ 3 Tangsteel New District Ironmaking Business Department, Hebei Iorn \& Steel Group, Tangshan 063000, China; \\ dongchaoaizww@163.com \\ 4 Hebei Yanxing Machinery Co., Ltd., Zhangjiakou 075000, China; guayujibuzailai@sina.com \\ * Correspondence: xyding@mail.neu.edu.cn; Tel.: +86-024-8367-2068
}

check for updates

Citation: Liu, C.; Ding, X.; Liu, H.; Yan, X.; Dong, C.; Wang, J. Numerical Analysis on Characteristics of Reduction Process within a Pre-Reduction Rotary Kiln. Metals 2021, 11, 1180. https://doi.org/ $10.3390 / \operatorname{met} 11081180$

Academic Editor: Thomas Echterhof

Received: 21 June 2021

Accepted: 22 July 2021

Published: 25 July 2021

Publisher's Note: MDPI stays neutral with regard to jurisdictional claims in published maps and institutional affiliations.

Copyright: (c) 2021 by the authors. Licensee MDPI, Basel, Switzerland. This article is an open access article distributed under the terms and conditions of the Creative Commons Attribution (CC BY) license (https:// creativecommons.org/licenses/by/ $4.0 /)$.

\begin{abstract}
The reduction process inside the ore pre-reduction rotary kiln involves a series of physicochemical reactions, and in-depth understanding of the reduction behavior is helpful to improve the product quality and productivity. This paper reports a three-dimensional steady state mathematical model based on computational fluid dynamics, which considers heat transfer, mass transfer and chemical reactions inside the rotary kiln. A user-defined functions (UDFs) program in C language is developed to define physical parameters and chemical reactions, and calculate the heat and mass transfer between freeboard and bed regions. The model is validated by measurement data and is then used to investigate the detailed information inside the rotary kiln. The results show that there is a temperature gradient in the bed, which is maximal near the kiln tail and decreases gradually as the reduction process progresses. The result also confirms that the reduction of $\mathrm{FeO}$ to $\mathrm{Fe}$ is the limiting step of the whole reduction process because this reaction requires a higher reduction potential. Furthermore, the influence of $\mathrm{C} / \mathrm{O}$ mole ratio and fill degree are analyzed by comparing the average bed temperature, reduction potential and metallization ratio.
\end{abstract}

Keywords: rotary kiln; reduction process; numerical simulation; pre-reduction

\section{Introduction}

As the most efficient technique, blast furnace ironmaking is currently the most widely used ironmaking process. However, it has inherent defects, such as long process, high dependence on coke, environmental pollution and so on. Additionally, with the depletion of coking coal and the strict emission standards of various countries, developing an alternative ironmaking process has always been a hot topic [1,2]. In recent decades, many research institutions and steel companies have carried out research on smelting reduction technology [3-6]. Among such research, a new smelting reduction process for iron ore processing has been presented by China Iron and Steel Research Institute Group (CISRI) [7,8]. The core of the process consists of two reactors: one is the pre-reduction rotary kiln, and the other one is the smelting reduction furnace. The main purpose of this process using a reliable rotary kiln as a pre-reduction reactor is to use the thermal energy and chemical energy of gas from the final reduction reactor to lighten the load of iron oxide reduction in the smelting reduction process, further improving the energy utilization of the whole system. Undoubtedly, the stable pre-reduction process is also the necessary guarantee for the smelting reduction process. Therefore, it is necessary to study the characteristics of a rotary kiln-based process on the reduction behavior of iron oxide.

Due to the enclosed process and the limitation of measuring equipment, it is difficult to directly obtain the comprehensive information by measurement. To solve this problem, 
many researchers have suggested employing mathematical methods. For example, Kingsley et al. [9] established a one-dimensional model of mass and energy transfer based on the FORTRAN program, and the obtained result provides a powerful approach for kiln operational optimization. However, due to the one-dimensional nature, the mass and energy balance equations are solved for the solid and gas assuming only axial temperature variation, that is, the solid and gas phases are fully mixed in cross-section, which is obviously far from the actual production. With the development of computational fluid dynamics (CFD), the numerical simulation technique has been widely used to solve such problems. A two-dimensional numerical simulation has been frequently used. Mujumdar et al. $[10,11]$ developed a comprehensive framework based on a two-dimensional model. They divided the computational domain into two regions: freeboard region and bed region, and then connected heat and mass transfer through a common interface. The model was able to predict qualitative and quantitative information about the key parameters. Furthermore, a similar approach was used by Gaurav et al. $[12,13]$ to investigate the influence of input parameters on the metallization ratio and temperature profile. Unfortunately, the two-dimensional model only considers one axial section of the rotary kiln, which makes it difficult to reflect the overall behavior of the rotary kiln. In order to be more relevant to practical production, it is necessary to develop a more practical three-dimensional computational fluid dynamics (CFD) model. Manju et al. [14] developed a three-dimensional numerical model of the pneumatic coal injection and combustion process using the Eulerian-Lagrangian approach. The influence of operating parameters such as particle size distribution and wall temperature on the distribution of injected particles was investigated. However, the reduction process in the bed region was not included. In fact, the flame stability, combustion characteristics and temperature distribution directly affect the reduction process and product quality, and the release of gas from the bed region also affects the distribution of gas and temperature in the freeboard region.

As mentioned above, this work proposed a strategy of a three-dimensional steady state mathematical model with the Eulerian method to investigate the characteristics inside the rotary kiln. This model involved mass, momentum and heat transfers, as well as combustion and reduction reactions both in the freeboard and bed regions. The simulation results show detailed information from inside the rotary kiln, such as the temperature field, variation of gas and solid phase species. Additionally, the effects of key operational parameters on the average bed temperature, reduction potential and metallization ratio are discussed. These findings are helpful to control and optimize the reduction process in the pre-reduction rotary kiln.

\section{Model Description}

\subsection{Description of the Process and Assumption}

The schematic diagram of the pre-reduction rotary kiln is shown in Figure 1. The kiln is $48 \mathrm{~m}$ long, with a $2.3 \mathrm{~m}$ internal diameter and is inclined by 2 degrees. In order to obtain the appropriate temperature profile, the air supply was staged, and five blowers were placed around the kiln at equal spacing to inject air. The raw materials were charged from the kiln tail in a predetermined ratio and heated by the hot flue gas flowing in reverse direction. The iron oxide was gradually reduced to metallic iron, and then the products of kiln were hot-charged into the smelting reduction furnace.

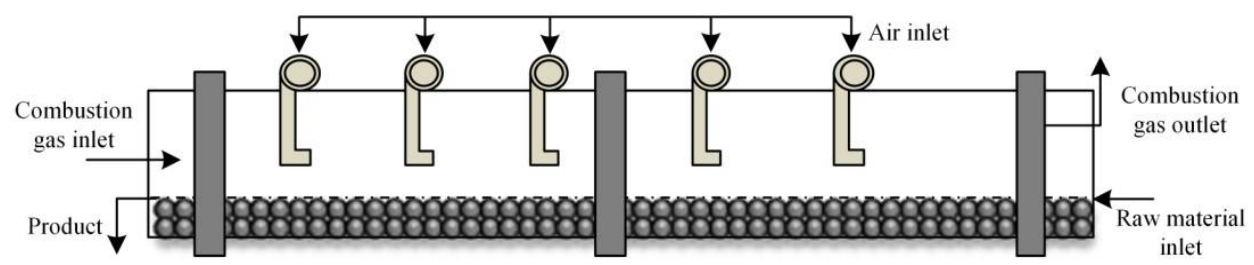

Figure 1. Schematic diagram of the pre-reduction rotary kiln. 
The reduction process in the rotary kiln is complicated, including mass transfer, heat transfer, various chemical reactions and so on. Hence, it is necessary to make some simplifications for developing a mathematical model. In this study, the rotary kiln is divided into two separate regions: freeboard region and bed region, as shown in Figure 2. It is assumed that only gas phase exists in the freeboard region, and both gas and solid phases exist in the bed region. The two regions are coupled through a common boundary, and mass transfer and heat exchange occur between freeboard region and bed region via this boundary.

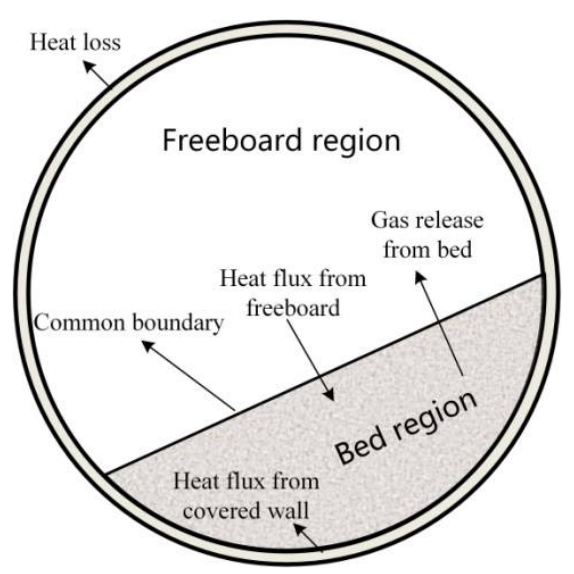

Figure 2. Heat and mass transfer between freeboard region and bed region.

\subsection{Governing Equations}

In this work, the rotary kiln model is a 3D steady-state model. Both gas and solid phases are treated as interpenetrating continua phases using the Eulerian method. The governing equations of mass, momentum, energy and species transport for the gas phase and solid phase can be written as follows:

$$
\nabla\left(\varepsilon_{p} \cdot \rho_{p} \cdot \phi \cdot \vec{v}_{p}\right)=\nabla\left(\varepsilon_{p} \cdot \Gamma_{\phi} \cdot \nabla(\phi)\right)+S_{\phi}
$$

where the diffusive coefficient $\left(\Gamma_{\phi}\right)$, variable $(\phi)$ and source term $\left(S_{\phi}\right)$ change with different kinds of governing equations, as summarized in Table 1.

Table 1. Variables in Equation (1).

\begin{tabular}{ccccc}
\hline Phase & Eq. & $\phi$ & $\Gamma_{\phi}$ & $S_{\phi}$ \\
\hline \multirow{4}{*}{ Gas } & Mass & 1 & 0 & $S_{\phi, g}$ \\
& Momentum & $\vec{v}_{g}$ & 0 & $\varepsilon_{g}\left(-\nabla P+\rho_{g} \cdot \vec{g}\right)+\vec{F}_{g s}$ \\
& Energy & $H_{g}$ & $\lambda_{g} / C_{P, g}$ & $h_{g s} A_{s}\left(T_{g}-T_{s}\right)+M_{o} \cdot \sum_{n=1}^{n}\left(R_{n} \cdot \Delta H_{n}^{T}\right)$ \\
& Species $i$ & $Y_{i, g}$ & $\rho_{g} D_{i}$ & $\sum_{k} R_{i, k} M_{i}$ \\
\hline \multirow{4}{*}{ Solid } & Mass & 1 & 0 & $S_{\phi, s}$ \\
& Momentum & $\vec{v}_{s}$ & 0 & $\varepsilon_{s}\left(-\nabla P+\rho_{s} \cdot \vec{g}\right)-\vec{F}_{g^{s}}$ \\
& Energy & $H_{s}$ & $\lambda_{s, e f f} / C_{P, s}$ & $h_{g s} A_{s}\left(T_{s}-T_{g}\right)-M_{o} \cdot \sum_{n=1}^{n}\left(R_{n} \cdot \Delta H_{n}^{T}\right)$ \\
& Species $j$ & $Y_{j, s}$ & $\rho_{s} D_{j}$ & $\sum_{k} R_{j, k} M_{j}$ \\
\hline
\end{tabular}




\subsection{Reaction Kinetics Model}

\subsubsection{Coal Devolatilization}

In the coal devolatilization process, it is considered that coal forms volatile matter and char in the gas phase and solid phase, respectively [15]. This process consists of two steps and can be described as follows:

$$
\begin{gathered}
\text { Coal }=\psi_{1} \mathrm{Char}+\text { Volatile matter } \\
\text { Volatile matter }=\psi_{2} \mathrm{CO}+\psi_{3} \mathrm{CO}_{2}+\psi_{4} \mathrm{H}_{2}+\psi_{5} \mathrm{H}_{2} \mathrm{O}+\psi_{6} \mathrm{CH}_{4}+\psi_{7} \mathrm{~N}_{2}
\end{gathered}
$$

The $\psi$ is the mass fraction of pyrolysis products, which is determined by the coal proximate and elemental analysis [16]. Moreover, the release of individual gas species from volatile matter is assumed to be a self-degradation [17], and the first-order reaction model developed by Donskoi was used [18]:

$$
R_{v i}=k_{v i, 0} \exp \left(-\frac{E_{v a, i}}{R T}\right) \frac{W_{v i}}{M_{v i}}
$$

\subsubsection{Homogeneous Reaction}

In this model, the solid-solid reactions are neglected because they only take place at the contact surface of particles. For gas-gas reactions, gases' combustion and watergas shift reactions are mainly considered. In the complex turbulent reacting flow, the reaction rate is usually controlled by chemical reaction kinetics and turbulent mixing rate. Therefore, the finite rate/eddy-dissipation model was adopted to describe the influence of turbulence-chemistry interaction on the reaction process [19]. This model computes both the Arrhenius rate and the mixing rate, and the smaller is favored. The kinetic parameters of homogenous reactions are shown in Table 2 . The reaction rates can be calculated by the following equations:

$$
\begin{gathered}
\hat{R}_{i, r}=\left(v^{\prime \prime}{ }_{i, r}-v^{\prime}{ }_{i, r}\right)\left(k_{f, r} \prod_{j=1}^{N_{r}}\left[C_{j . r}\right]^{\eta^{\prime}{ }_{j, r}}-k_{b, r} \prod_{j=1}^{N_{r}}\left[C_{j, r}\right]^{\eta^{\prime \prime}, r}\right) \\
R_{i, r}=\min \left\{v^{\prime}{ }_{i, r} M_{w, i} A \rho_{\frac{\varepsilon}{k}}^{\varepsilon} \min _{R}\left(\frac{Y_{R}}{v_{R, r}^{\prime} M_{w, R}}\right), v^{\prime}{ }_{i, r} M_{w, i} A B \frac{\varepsilon}{k} \frac{\sum_{p} Y_{p}}{\sum_{j}^{N} v_{j, r}^{n} M_{w, j}}\right\}
\end{gathered}
$$

Table 2. Kinetic parameters of homogenous reactions [20,21].

\begin{tabular}{ccccc}
\hline Reaction & $A_{r}\left(\mathbf{s}^{-\mathbf{1}}\right)$ & $\left.\boldsymbol{E}_{\boldsymbol{a}} \mathbf{( J / k m o l}\right)$ & $\beta_{r}$ & Reaction Order \\
\hline $2 \mathrm{CO}+\mathrm{O}_{2}=2 \mathrm{CO}_{2}$ & $2.2 \times 10^{12}$ & $1.7 \times 10^{8}$ & 0 & {$[\mathrm{CO}]\left[\mathrm{O}_{2}\right]$} \\
$2 \mathrm{H}_{2}+\mathrm{O}_{2}=2 \mathrm{H}_{2} \mathrm{O}$ & $6.8 \times 10^{15}$ & $1.67 \times 10^{8}$ & -1 & {$\left[\mathrm{H}_{2}\right]^{0.25}\left[\mathrm{O}_{2}\right]^{1.5}$} \\
$\mathrm{CO}+\mathrm{H}_{2} \mathrm{O}=\mathrm{CO}_{2}+\mathrm{H}_{2}$ & $2.75 \times 10^{9}$ & $8.4 \times 10^{7}$ & 0 & {$[\mathrm{CO}]\left[\mathrm{H}_{2} \mathrm{O}\right]$} \\
\hline
\end{tabular}

\subsubsection{Heterogeneous Reaction}

For gas-solid reactions, the main reactions are the carbon gasification (by $\mathrm{CO}_{2}$ and $\mathrm{H}_{2} \mathrm{O}$ ) and the reduction of iron oxides (by $\mathrm{CO}$ and $\mathrm{H}_{2}$ ). Since the pellet is made of very fine particles, the time scale for the reactions at high temperature is much shorter than the time scale for diffusion in the pores. Therefore, it can reasonably be assumed that pores will not contribute significantly to the reaction rate, that is, the gas-solid reactions are limited to the reaction interface. The shrinking core model developed by Sun and Lu was used to describe the heterogeneous reaction process [22,23]. This model takes into account the effects of heat and mass transfer on the reaction rate. The kinetic parameters of these 
heterogeneous reactions are shown in Table 3. The reaction rates can be calculated by the following equations:

$$
\begin{gathered}
R_{i}^{C O}=S_{f, i} n_{i} 4 \pi r_{i}^{2}\left(1-f_{i}\right)^{\frac{2}{3}} k_{i, 0} \exp \left(-\frac{E_{a, i}}{R T}\right)\left(C_{c o}-\frac{C_{c o_{2}}}{K_{e, i}}\right) \\
R_{i}^{H_{2}}=S_{f, i} n_{i} 4 \pi r_{i}^{2}\left(1-f_{i}\right)^{\frac{2}{3}} k_{i, 0} \exp \left(-\frac{E_{a, i}}{R T}\right)\left(C_{H_{2}}-\frac{C_{H_{2} O}}{K_{e, i}}\right) \\
R_{c}^{C O_{2}}=S_{f, c} n_{c} 4 \pi r_{c}^{2}\left(1-f_{c}\right)^{\frac{2}{3}} k_{c, 0} \exp \left(-\frac{E_{a, c}}{R T}\right)\left(C_{c o_{2}}-\frac{C_{c o}^{2}}{K_{e, c}}\right) \\
R_{c}^{H_{2} O}=S_{f, c} n_{c} 4 \pi r_{c}^{2}\left(1-f_{c}\right)^{\frac{2}{3}} k_{c, 0} \exp \left(-\frac{E_{a, c}}{R T}\right)\left(C_{H_{2} O}-\frac{C_{H_{2}} \cdot C_{C O}}{K_{e, c}}\right)
\end{gathered}
$$

\begin{tabular}{|c|c|c|c|c|}
\hline Reactions & $k_{i, 0}\left(\mathrm{~m} \cdot \mathrm{s}^{-1}\right)$ & $E_{a}(\mathrm{~J} / \mathrm{mol})$ & $K_{e}$ & Rate Expressions \\
\hline $\mathrm{C}+\mathrm{CO}_{2}=2 \mathrm{CO}$ & $1.87 \times 10^{8}$ & 221,800 & $\exp (-20,765.92 / \mathrm{T}+32.8)$ & Equation (9) \\
\hline $\mathrm{C}+\mathrm{H}_{2} \mathrm{O}=\mathrm{CO}+\mathrm{H}_{2}$ & $6.05 \times 10^{5}$ & 172,700 & $\exp (-16,142.19 / \mathrm{T}+28.16)$ & Equation (10) \\
\hline $3 \mathrm{Fe}_{2} \mathrm{O}_{3}+\mathrm{CO}=2 \mathrm{Fe}_{3} \mathrm{O}_{4}+\mathrm{CO}_{2}$ & 2700 & 113,859 & $\exp (5815.5 / \mathrm{T}+5.5076)$ & Equation (7) \\
\hline $3 \mathrm{Fe}_{2} \mathrm{O}_{3}+\mathrm{H}_{2}=2 \mathrm{Fe}_{3} \mathrm{O}_{4}+\mathrm{H}_{2} \mathrm{O}$ & 160 & 92,000 & $\exp (2065 / T+8.102)$ & Equation (8) \\
\hline $\mathrm{Fe}_{3} \mathrm{O}_{4}+\mathrm{CO}=3 \mathrm{FeO}+\mathrm{CO}_{2}$ & 23 & 71,100 & $\exp (-4685.22 / \mathrm{T}+5.19)$ & Equation (7) \\
\hline $\mathrm{Fe}_{3} \mathrm{O}_{4}+\mathrm{H}_{2}=3 \mathrm{FeO}+\mathrm{H}_{2} \mathrm{O}$ & 30 & 63,600 & $\exp (-1857.51+1.01)$ & Equation (8) \\
\hline $\mathrm{FeO}+\mathrm{CO}=\mathrm{Fe}+\mathrm{CO}_{2}$ & 17 & 69,454 & $\exp (2376.46 / \mathrm{T}-2.82)$ & Equation (7) \\
\hline $\mathrm{FeO}+\mathrm{H}_{2}=\mathrm{Fe}+\mathrm{H}_{2} \mathrm{O}$ & 30 & 63,600 & $\exp (-1857.51 / \mathrm{T}+1.01)$ & Equation (8) \\
\hline
\end{tabular}

Table 3. Kinetic parameters of heterogeneous reactions [24].

\subsection{Turbulence Model}

The standard $k-\varepsilon$ model was adopted to simulate the gas phase turbulence in the freeboard region. For the bed region, the details of the movement of solids in the radial direction and variation of bed height are ignored, and solids are regarded as pseudohomogeneous fluids. The flow velocity of solid particles in the axial direction is very small, and the turbulence has little effect on the reduction process. Hence, the bed region is assumed to be a laminar zone. The standard $\mathrm{k}-\varepsilon$ model is a two-equation turbulence model based on the transport equation of turbulence kinetic energy $(k)$ and its dissipation rate $(\varepsilon)$. The expression is as follows [25,26]:

$$
\begin{gathered}
\frac{\partial(\rho k)}{\partial t}+\nabla(\rho k v)=\nabla\left[\left(\mu+\frac{\mu_{t}}{\sigma_{k}}\right) \cdot \nabla k\right]+C_{k}-\rho \varepsilon \\
\frac{\partial(\rho \varepsilon)}{\partial t}+\nabla(\rho \varepsilon v)=\nabla\left[\left(\mu+\frac{\mu_{t}}{\sigma_{\varepsilon}}\right) \cdot \nabla \varepsilon\right]+\frac{\varepsilon}{k}\left(C_{\varepsilon 1} C_{K}-C_{\varepsilon 2} \rho \varepsilon\right)
\end{gathered}
$$

where $C_{\varepsilon 1}=1.44, C_{\varepsilon 2}=1.92, C_{\mu}=0.09, \sigma_{k}=1.0, \sigma_{\varepsilon}=1.3$.

\subsection{Radiation Model}

In this work, the discrete ordinates (DO) radiation model was used to calculate the radiation flux. The $\mathrm{DO}$ model is suitable for solving radiation problem in the entire range of optical thicknesses, especially for the problem of local heat source. The model solves the radiative transfer equation (RTE) for a finite number of discrete solid angles, each associated with a vector direction fixed in the global Cartesian system [27], and the equation can be written as follows:

$$
\nabla(I(\vec{r}, \vec{s}) \vec{s})+\left(a+\sigma_{s}\right) I(\vec{r}, \vec{s})=a n^{2} \frac{\sigma T^{4}}{\pi}+\frac{\sigma_{s}}{4 \pi} \int_{0}^{4 \pi} I\left(\vec{r}, \overrightarrow{s^{\prime}}\right) \Phi\left(\vec{s}, \overrightarrow{s^{\prime}}\right) d \Omega
$$


where $a$ is the absorption coefficient of gas phase. Here, the weighted-sum-of-gray-gases model (WSGGM) is used to specify the variable absorption coefficient [28].

\subsection{Heat Transfer in the Bed Region}

As shown in Figure 2, the heat transfer mechanisms of the top and bottom surfaces of the bed are different. The top surface of the bed is heated mainly by convection and radiation from the gas and radiation from the inner exposed wall. The heat flux of top surface can be defined as $[29,30]$ :

$$
\begin{gathered}
q_{\text {top }}=h_{g b}\left(T_{g}-T_{b}\right)+e_{g} X_{b g}\left(E_{g}-J_{b}\right)+\left(1-e_{g}\right) X_{b w}\left(J_{e w}-J_{b}\right) \\
h_{g b}=0.46 \lambda_{g} \operatorname{Re}^{0.535} \operatorname{Re}_{\omega}^{0.104} \eta_{s}^{-0.341} / D_{e}
\end{gathered}
$$

The bottom surface of the bed receives heat from conduction, convection and radiation from the covered wall. Tscheng and Watkinson [30] have reported the combined heat transmission coefficient between bottom surface and covered wall, and the heat flux is given by:

$$
\begin{aligned}
& q_{\text {bottom }}=h_{w b}\left(T_{w}-T_{b}\right) \\
& h_{w b}=\frac{11.6 \lambda_{s}}{R \theta}\left(\frac{\omega R^{2} \theta}{\alpha_{s}}\right)^{0.3}
\end{aligned}
$$

Moreover, the rotation speed of the pre-reduction rotary kiln is very low at $0.6 \mathrm{rpm}$, and the active layer makes up a very small portion of the bed region. Hence, it is reasonable to treat the heat transfer process of the bed in the rotary kiln approximately according to the heat transfer process of the plug flow region, which is a common method and has been widely used [31-33]. The expression of effective thermal conductivity in the bed is as follows [33]:

$$
\lambda_{s, e f f}=\frac{\varepsilon_{s}}{\frac{1}{\lambda_{s}}+\frac{1}{4 \sigma e d_{p} T^{3}}}+4 \varepsilon_{g} \sigma e d_{p} T^{3}
$$

\subsection{Numerical Method and Boundary Condition}

Figure 3 shows the geometric model of the rotary kiln. To simplify the model and improve the grid quality, the elbows are simplified with cylinders as air inlets, which has no effect on the simulation results. Figure 4 presents the computational grid of the rotary kiln created using ICEM CFD, containing 4,118,224 hexahedral cells in all regions. The CFD software FLUENT was used for the simulation process. The segregated independent and 3D steady solver was adopted. The governing equations were discretized with second order upwind scheme using the control volume method and solved by SIMPLE arithmetic, and the simulation process was considered as convergence when the residuals are less than $1 \times 10^{-5}$. Furthermore, the mass transfer and heat exchange on the interface were defined as mass source and energy sink, and the UDF program in C language was developed and linked to FLUENT to calculate the energy absorbed by bed surface and gas escaping from the bed surface.

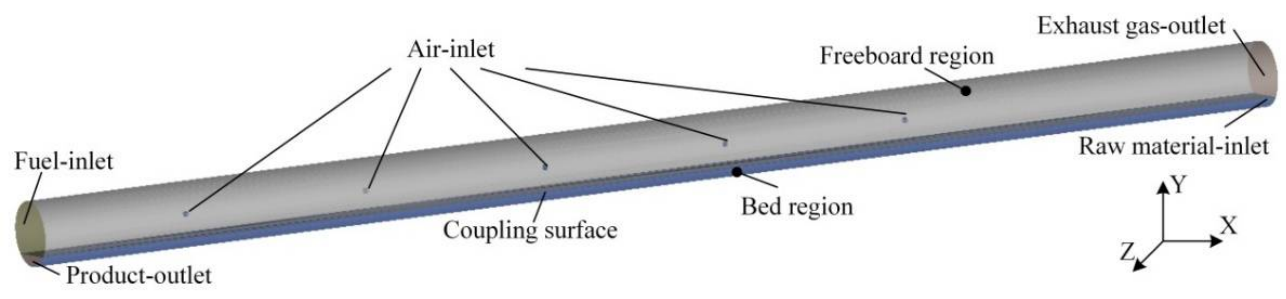

Figure 3. Simplified geometric model of the rotary kiln. 


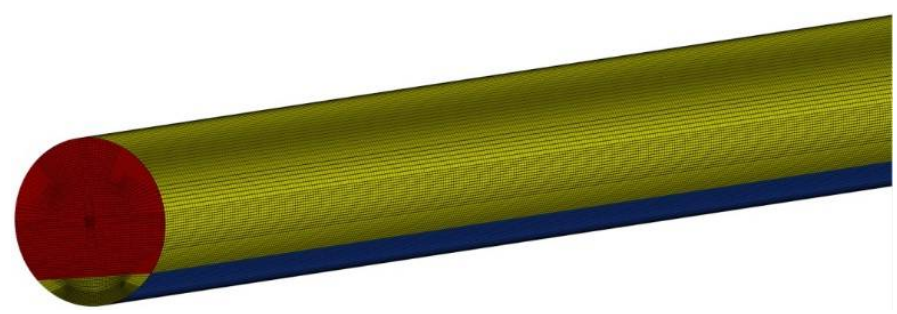

Figure 4. Computation mesh.

The boundary condition of the rotary kiln for numerical simulation is shown in Figure 3. The boundary conditions of fuel-inlet, air-inlet and raw material-inlet are "massflow-inlet". The boundary conditions of gas-outlet and product-outlet are "pressure-outlet". The mass flow rate and temperature of fuel gas are $0.468 \mathrm{~kg} / \mathrm{s}$ and $1473 \mathrm{~K}$, respectively. The mass flow rate and temperature of raw material are $2.833 \mathrm{~kg} / \mathrm{s}$ and $300 \mathrm{~K}$, respectively. The mass flow rate and temperature of combustion air are $0.443 \mathrm{~kg} / \mathrm{s}$ and $300 \mathrm{~K}$, respectively. The particle size was set to $13 \mathrm{~mm}$. The chemical composition of fuel gas and raw material are listed in Tables 4 and 5. In addition, the shear condition at the kiln wall is the no-slip condition, and heat transfer coefficient for convection and radiation from kiln wall to environment was calculated by [34]:

$$
\begin{gathered}
h_{w e}^{c}=\frac{0.11 k_{a}}{D_{s h}}\left(\left(0.5 \operatorname{Re}_{\omega}^{2}+G r\right) \operatorname{Pr}_{a}\right)^{0.35} \\
h_{w e}^{r}=\sigma e \frac{T_{s h}^{4}-T_{a}^{4}}{T_{s h}-T_{a}}
\end{gathered}
$$

Table 4. Chemical composition of fuel gas.

\begin{tabular}{cccccc}
\hline Species & $\mathbf{C O}$ & $\mathrm{CO}_{2}$ & $\mathbf{H}_{2}$ & $\mathbf{H}_{\mathbf{2}} \mathbf{O}$ & $\mathbf{N}_{\mathbf{2}}$ \\
\hline Mole fraction & 56.7 & 20.0 & 14.3 & 4.8 & 4.2 \\
\hline
\end{tabular}

Table 5. Chemical composition of raw material.

\begin{tabular}{ccccccccccc}
\hline Species & $\mathrm{Fe}_{2} \mathrm{O}_{3}$ & $\mathrm{FeO}$ & $\mathrm{Al}_{2} \mathrm{O}_{3}$ & $\mathrm{SiO}_{2}$ & $\mathrm{CaO}$ & $\mathbf{M g O}$ & $\mathrm{TiO}_{2}$ & $\mathrm{C}$ & $\mathrm{Vol}$ & $\mathrm{Ash}$ \\
\hline Mass fraction & 38.6 & 24.6 & 2.6 & 3.5 & 1.1 & 2.7 & 5.0 & 15.34 .7 & 1.9 \\
\hline
\end{tabular}

\section{Results and Discussion}

\subsection{Model Validation}

The comparison between the computational and measured results is listed in Table 6, mainly composed of gas composition and temperature of exhaust gas at the kiln tail, metallization rate (MR) of the reduced product outlet and relative error. The metallization rate (MR) and relative error are given by Equations (19) and (20). As shown in Table 6, the simulation results are in good agreement with the measured value. The maximum relative error between measured and calculated results is $10.8 \%$. Generally speaking, the model in this work is reasonably reliable for predicting the inner characteristics of the rotary kiln.

$$
\begin{aligned}
& M R=\frac{w_{\mathrm{Fe}}}{w_{\mathrm{Fe}}+\frac{56}{72} \times w_{\mathrm{FeO}}+\frac{112}{160} \times w_{\mathrm{Fe}_{2} \mathrm{O}_{3}}+\frac{168}{232} \times w_{\mathrm{Fe}_{3} \mathrm{O}_{4}}} \\
& \text { Relative Error }=\frac{\mid \text { Measured value }- \text { Simulated value } \mid}{\text { Measured value }}
\end{aligned}
$$


Table 6. Comparison between measured and simulated results.

\begin{tabular}{cccc}
\hline Parameters & Measured & Simulated & Relative Error \\
\hline $\mathrm{CO}(\%)$ & 19.4 & 20.2 & $4.3 \%$ \\
$\mathrm{CO}_{2}(\%)$ & 24.2 & 22.9 & $5.1 \%$ \\
$\mathrm{H}_{2}(\%)$ & 8.1 & 9.0 & $10.8 \%$ \\
$\mathrm{H}_{2} \mathrm{O}(\%)$ & 15.2 & 14.9 & $1.6 \%$ \\
$\mathrm{~T}(\mathrm{~K})$ & 1023 & 1002 & $2.1 \%$ \\
$\mathrm{Metal}(\%)$ & 70.0 & 72.4 & $3.4 \%$ \\
\hline
\end{tabular}

\subsection{Basic Analysis}

\subsubsection{Temperature Distribution}

Figure 5 displays the temperature distribution of the gas phase along the axial section of the pre-reduction rotary kiln. The high temperature zones near the flames due to combustion reactions of $\mathrm{H}_{2}$ and $\mathrm{CO}$ are visible, and the maximum temperature at the edge of flames is about $2200 \mathrm{~K}$. Moreover, the combustion-supporting air enters the rotary kiln through five different nozzles to form five combustion regions, which is beneficial to reasonably controlling the axial temperature distribution and preventing local high temperature zones near the bed surface.

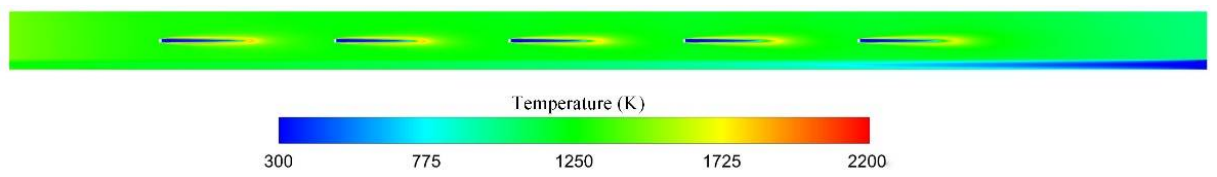

Figure 5. Temperature distribution of the gas phase along the axial section.

Figure 6 shows the temperature distribution of the solid phase within the bed crosssection at different positions. " $\mathrm{L}$ " represents the distance from the cross-section to the kiln tail. As expected, the temperature of the cross-section within the bed is not uniform, and there is a temperature gradient in the radial direction. The temperature of the bed surface and bottom is higher than that of the core. To better describe the evolution of temperature, the temperature of the cross-section along the axis of the rotary kiln is illustrated in Figure $7 . T_{\text {ave, }}, T_{\max }, T_{\min }$ and $\Delta T$ represent the average temperature, the maximum temperature, the minimum temperature, and the difference between maximum temperature and minimum temperature of the cross-section, respectively. After the raw materials are charged into the kiln at ambient temperature, the raw materials near the outer region are heated rapidly, while the heating rate of raw materials near the core region is relatively slow, and the temperature gradient at the kiln tail is larger than others. As the raw materials move toward the kiln head, the temperature gradient gradually decreases and changes gently after moving to the middle part of the kiln. This is mainly because the heating rate is restrained by carbon gasification reactions (by $\mathrm{CO}_{2}$ and $\mathrm{H}_{2} \mathrm{O}$ ), which are strongly endothermic reactions.
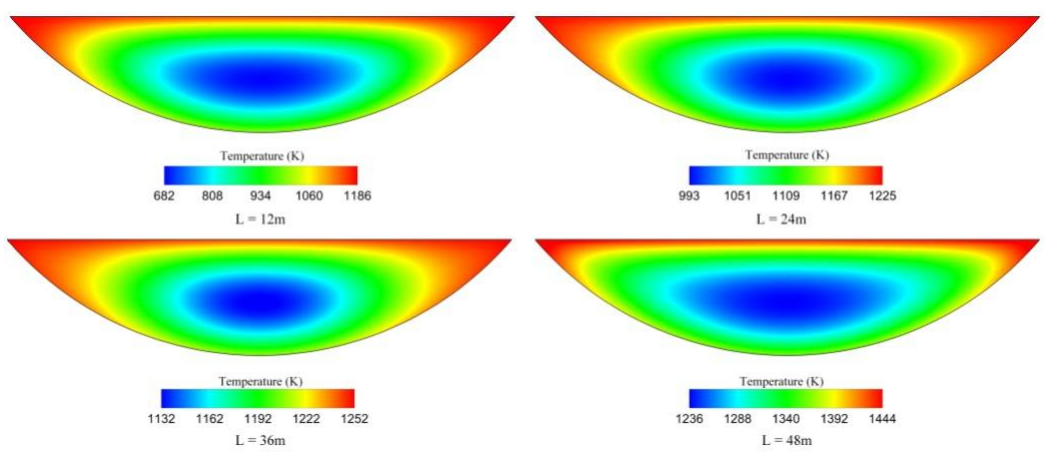

Figure 6. Temperature distribution of the solid phase within the bed cross-section. 


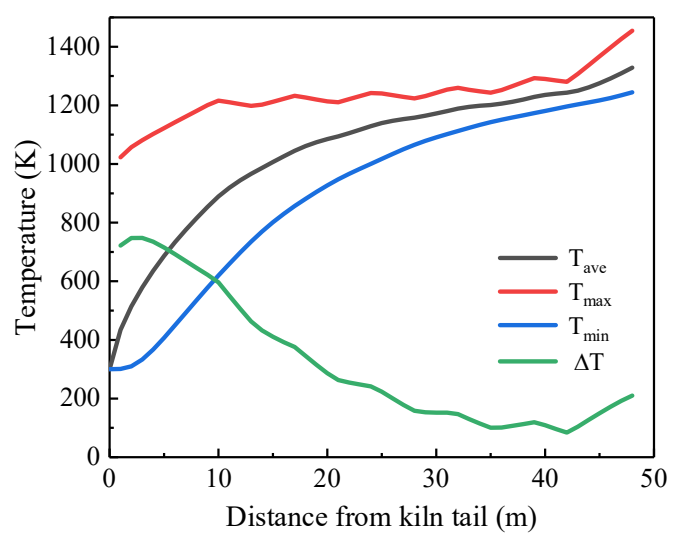

Figure 7. Temperature distribution of the cross-section along the axis of the rotary kiln.

\subsubsection{Distribution of Gas Composition}

The detailed information of the main gas species' distribution $\left(\mathrm{O}_{2}, \mathrm{CO}, \mathrm{H}_{2}, \mathrm{CO}_{2}, \mathrm{H}_{2} \mathrm{O}\right)$ in the rotary kiln is obtained by calculation. Figure 8 shows the contour of the gas phase in mass fraction along the axial section. To maintain the reducing atmosphere in the kiln, the air supply is insufficient. It can be seen that there is almost no $\mathrm{O}_{2}$ in the kiln except near the nozzles, which is beneficial to reducing the risk of re-oxidization of the metalized Fe. At the combustion reaction zones, a portion of $\mathrm{CO}$ and $\mathrm{H}_{2}$ are consumed rapidly. The concentrations of $\mathrm{CO}$ and $\mathrm{H}_{2}$ gradually decrease in the direction of gas flow; on the contrary, the concentrations of $\mathrm{H}_{2} \mathrm{O}$ and $\mathrm{CO}_{2}$ gradually increase.

Figure 9 shows the average mole fraction of gas species $\left(\mathrm{CO}, \mathrm{H}_{2}, \mathrm{CO}_{2}, \mathrm{H}_{2} \mathrm{O}\right)$ in the bed region as a function of distance from the kiln tail, which are the intermediate gases for the reduction of iron oxides by carbon. It is observed that the concentrations of gas species $(\mathrm{CO}$, $\mathrm{H}_{2}, \mathrm{CO}_{2}, \mathrm{H}_{2} \mathrm{O}$ ) increase linearly near the inlet of raw materials. This is mainly attributed to the rapid release of volatile matter. After that, the volatile mater is gradually exhausted and the concentrations of $\mathrm{H}_{2}$ and $\mathrm{H}_{2} \mathrm{O}$ gradually decrease. When the materials move to the middle of the rotary kiln, there is almost no $\mathrm{H}_{2}$ and $\mathrm{H}_{2} \mathrm{O}$ in the system. On the contrary, with the increase of material temperature, the rate of carbon gasification is accelerated. When the generation rate of $\mathrm{CO}$ exceeds its consumption rate, the concentration of $\mathrm{CO}$ keeps increasing. Moreover, the variation in concentration of $\mathrm{CO}_{2}$ is different from that of $\mathrm{CO}$. The increase of $\mathrm{CO}_{2}$ concentration in the early stage of reduction process may be attributed to the generation of volatile matter and reduction of iron oxide by $\mathrm{CO}$, while the decrease of $\mathrm{CO}_{2}$ concentration in the later stage of the reduction process is attributed to the rapid consumption of carbon gasification.

\subsubsection{Variation of Iron Oxides}

Figure 10 presents the average mass fraction of solid species ( $\left.\mathrm{Fe}, \mathrm{FeO}, \mathrm{Fe}_{2} \mathrm{O}_{3}, \mathrm{Fe}_{3} \mathrm{O}_{4}\right)$ in the bed region as a function of distance from the rotary kiln tail. When the material temperature is higher than $570{ }^{\circ} \mathrm{C}$, the reduction process of $\mathrm{Fe}_{2} \mathrm{O}_{3}$ to Fe includes three steps: $\mathrm{Fe}_{2} \mathrm{O}_{3} \rightarrow \mathrm{Fe}_{3} \mathrm{O}_{4} \rightarrow \mathrm{FeO} \rightarrow \mathrm{Fe}$. The reduction of $\mathrm{Fe}_{2} \mathrm{O}_{3}$ to $\mathrm{Fe}_{3} \mathrm{O}_{4}$ occurs rapidly, which is due to the low reduction potential required for this reaction. It can be seen that this reaction has been completed when the material reaches the middle of kiln. Since the reduction rate of $\mathrm{Fe}_{2} \mathrm{O}_{3}$ to $\mathrm{Fe}_{3} \mathrm{O}_{4}$ is faster than that of $\mathrm{Fe}_{3} \mathrm{O}_{4}$ to $\mathrm{FeO}$, the concentration of $\mathrm{Fe}_{3} \mathrm{O}_{4}$ increases first and then decreases. Once $\mathrm{Fe}_{3} \mathrm{O}_{4}$ is completely reduced to $\mathrm{FeO}$, only the reduction of $\mathrm{FeO}$ to Fe remains, and then the concentration of FeO decreases gradually. Obviously, the reduction of $\mathrm{FeO}$ to $\mathrm{Fe}$ is the rate limiting step of the reduction process because this reaction requires a higher reduction potential. In addition, there is almost no $\mathrm{H} 2$ in the system after the materials reach the middle of the rotary kiln (Figure 9), and the reduction reaction of iron mainly occurs in the second half of the rotary kiln. Therefore, it can be considered that $\mathrm{H}_{2}$ makes little contribution to the reduction of $\mathrm{FeO}$ to $\mathrm{Fe}$, and $\mathrm{CO}$ is the major reducing agent for this reduction reaction. 


\subsection{Influences of $\mathrm{C} / \mathrm{O}$ Ratio}

The $\mathrm{C} / \mathrm{O}$ mole ratio is an important parameter in industrial production. To investigate the effect of $\mathrm{C} / \mathrm{O}$ mole ratio on reduction process, the $\mathrm{C} / \mathrm{O}$ mole ratio is set to $0.8,1.0,1.2$ and 1.4, respectively, and the fill degree of the rotary kiln is kept at $11.6 \%$. Figure 11 shows the variation of average bed temperature along the axial section with different $\mathrm{C} / \mathrm{O}$ mole ratios. It is clear that the trends of average bed temperature for different $\mathrm{C} / \mathrm{O}$ mole ratios are similar, and the heating rate is first fast and then slow. The fast heating rate in the early stage is mainly due to the large temperature gradient between the bed and surrounding environment. Moreover, the reductions of $\mathrm{Fe}_{2} \mathrm{O}_{3}$ and $\mathrm{Fe}_{3} \mathrm{O}_{4}$ are the main reactions in this stage, thus the amount of heat consumption by reactions is small. Besides, the average bed temperatures change very little between different $\mathrm{C} / \mathrm{O}$ mole ratios, which indicates that the effect of the $\mathrm{C} / \mathrm{O}$ mole ratio on the average bed temperature is negligible.

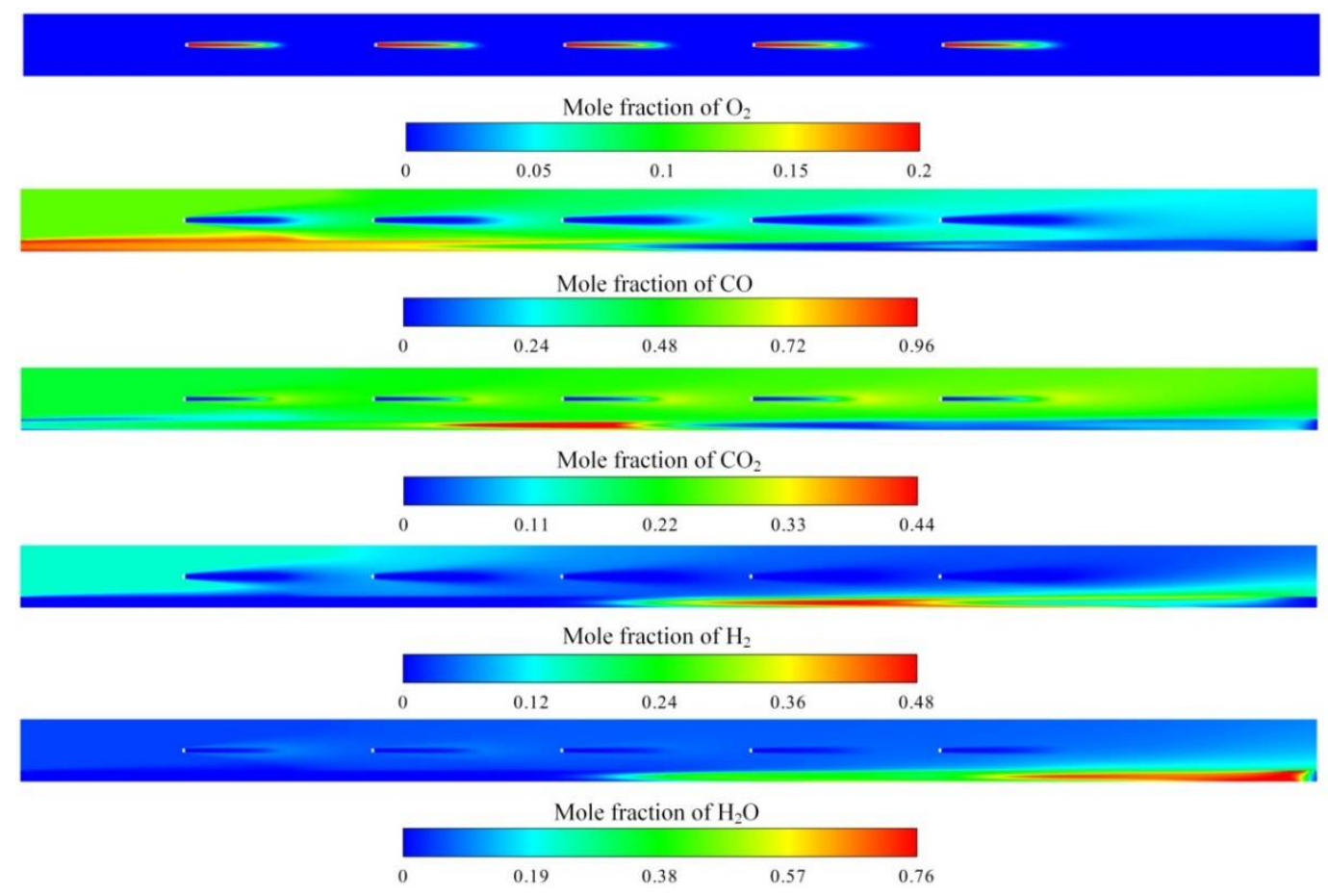

Figure 8. Composition distributions of the gas phase along the axial section.

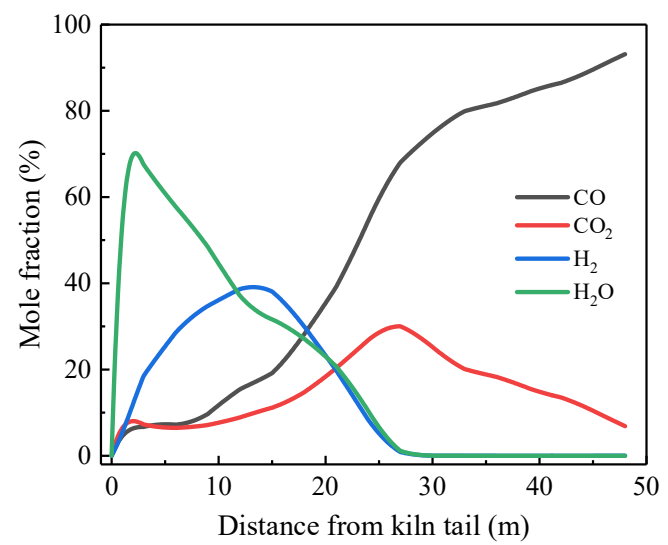

Figure 9. Average mole fraction of gas composition in the bed region along the axial section. 


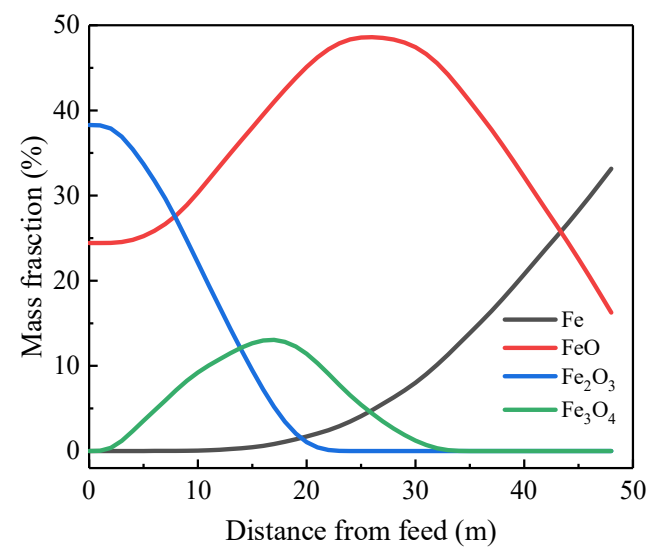

Figure 10. Average mass fraction of solid composition in the bed region along the axial section.

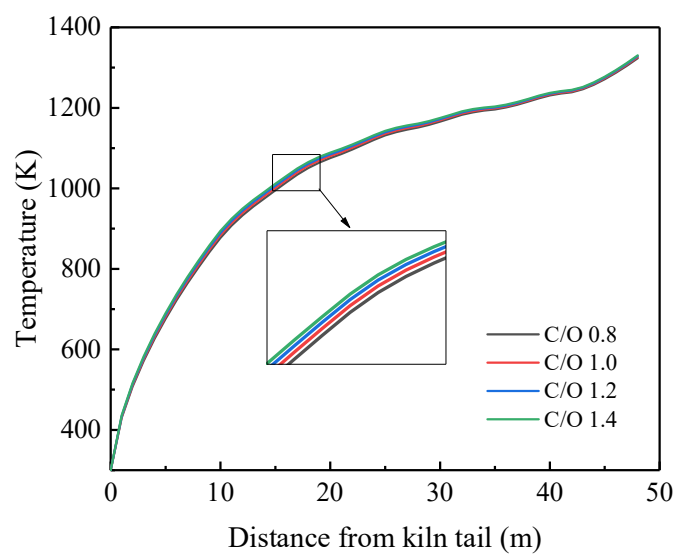

Figure 11. Average bed temperature along the axial section for different $\mathrm{C} / \mathrm{O}$ mole ratios.

The reduction potential is defined by Equation (23), which is an important index with which to evaluate the reduction ability of intermediate reducing gas. Figure 12 shows the variation of reduction potential along the axial section with different $\mathrm{C} / \mathrm{O}$ mole ratios. As shown in Figure 12, comparing the four simulation cases at the same position, the reduction potential increases significantly with the increase of $\mathrm{C} / \mathrm{O}$ mole ratio. In general, the reduction potential is determined by the gas composition, and the higher reduction potential represents the higher concentration of reducing gas. Clearly, the carbon concentration in the bed increases with the increase of $\mathrm{C} / \mathrm{O}$ mole ratio. This is helpful to accelerate the carbon gasification reactions, leading to an increase in the concentration of reducing gas.

$$
\text { Reduction Potential }=\frac{\varphi C_{\mathrm{O}}+\varphi_{\mathrm{H}_{2}}}{\varphi_{\mathrm{CO}}+\varphi_{\mathrm{H}_{2}}+\varphi_{\mathrm{CO}_{2}}+\varphi_{\mathrm{H}_{2} \mathrm{O}}}
$$

Figure 13 shows the variation of metallization rate along the axial section with different $\mathrm{C} / \mathrm{O}$ mole ratios. It can be observed that the decrease of $\mathrm{C} / \mathrm{O}$ mole ratio is unfavorable to the production of metallic iron. This can be explained by the obtained results from Figures 11 and 12. Both the average bed temperature and reduction potential are very important for the reduction process. Although the $\mathrm{C} / \mathrm{O}$ mole ratio has little effect on the average bed temperature, it has a strong effect on the reduction potential. At the same bed temperature, the higher reduction potential of reducing gas leads to a stronger reduction ability, which promotes the reduction of $\mathrm{FeO}$ to Fe. 


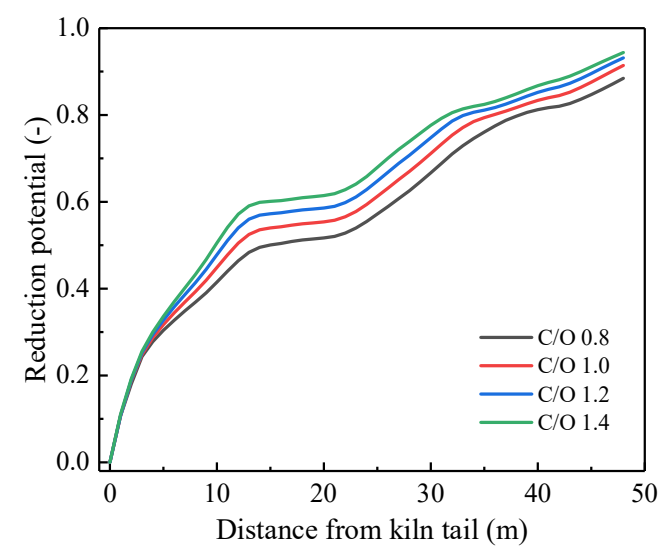

Figure 12. Reduction potential along the axial section for different $\mathrm{C} / \mathrm{O}$ mole ratios.

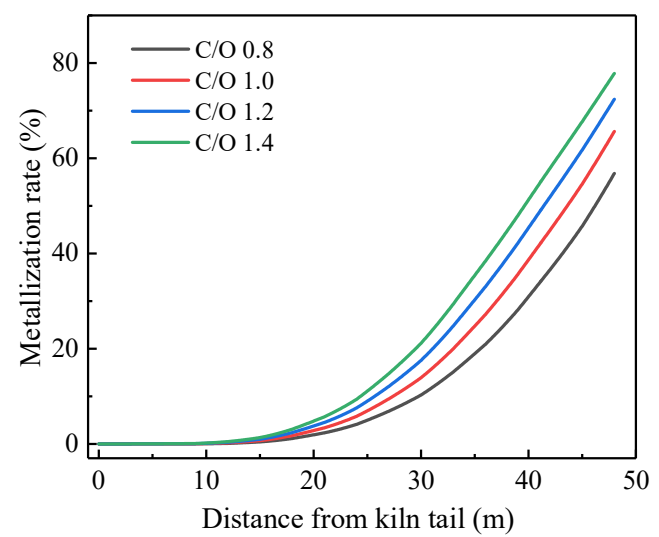

Figure 13. Metallization rate along the axial section for different $\mathrm{C} / \mathrm{O}$ mole ratio.

\subsection{Influences of Fill Degree}

In the previous discussion, the fill degree of the rotary kiln is fixed. This section examines the influence of fill degree on the reduction process in the rotary kiln, and the fill degree is set to $11.6 \%, 16.6 \%, 21.6 \%$ and $26.6 \%$, respectively. Figure 14 shows the variation of average bed temperature along the axial section for different fill degrees. It appears that the fill degree has a strong effect on the average bed temperature. As expected, the higher fill degree lengthens the path of heat transfer throughout the bed, which leads to lower bed temperature.

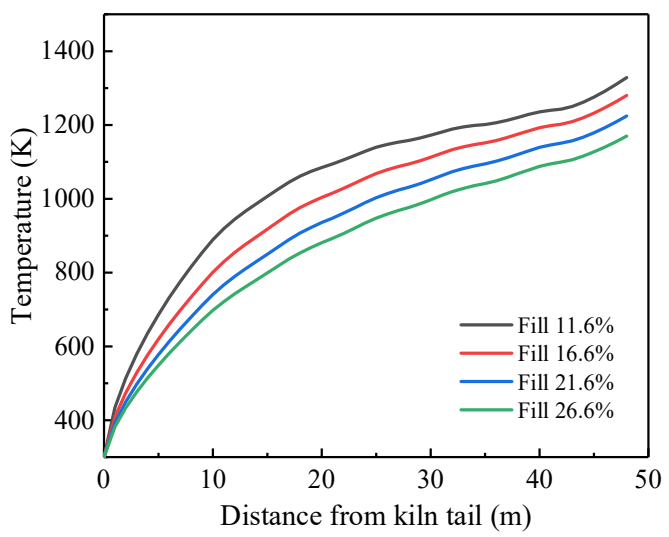

Figure 14. Average bed temperature along the axial section for different fill degrees. 
Figure 15 shows the variation of reduction potential along the axial section for different fill degrees. It is found that the reduction potential decreases with the increase of fill degree. The curves are mainly composed of three parts. In the first part, the reduction potential rapidly increases due to the release of volatile matter. With the increase of fill degree, the bed temperature decreases correspondingly, which weakens the release rate of volatile matter and prolongs the residence time in the first part. The second part is a period with a very slow rising rate, and the reduction potential remains nearly constant in this part. This implies that the supply of reducing gas just meets the requirement of reduction reactions. Similarly, the increase of the fill degree also extends the residence time of the second part. With the increases of bed temperature, the carbon gasification reactions become significant, and the reduction potential rises again, which marks the beginning of the third part and lasts until the product is discharged from the kiln head.

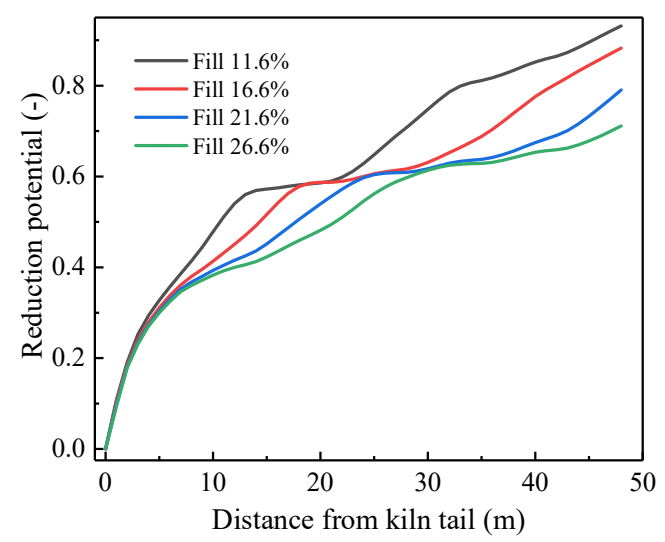

Figure 15. Reduction potential along the axial section for different fill degree.

Figure 16 shows the variation of metallization rate along the axial section for different fill degrees. It can be seen that there is almost no metallic iron in the bed at the early stage, and then the metallization rate gradually increases as the reduction reaction progresses. A lower metallization rate is found in the case of higher fill degree at the same position. When the fill degree increases to $26.6 \%$, the final metallization rate is only $26.3 \%$. This is because higher fill degree leads to lower bed temperature and lower reduction potential, which is unfavorable to the reduction reactions. Therefore, in order to ensure product quality, the fill degree should not be too high in practical production.

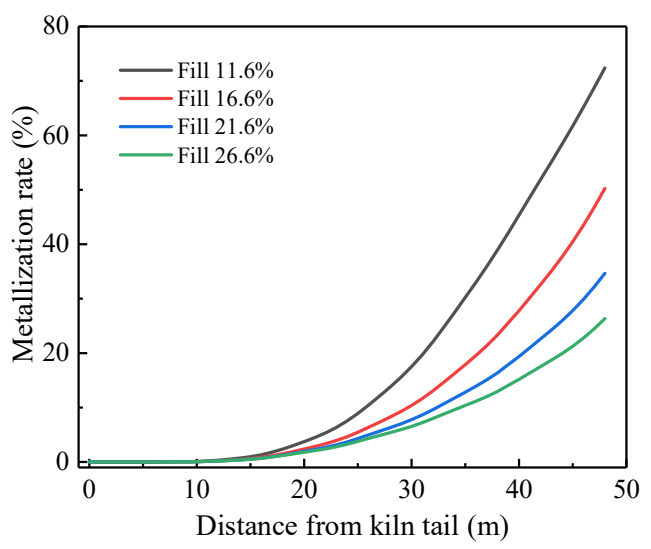

Figure 16. Metallization rate along the axial section for different fill degrees. 


\section{Conclusions}

In the present work, the reduction process in a pre-reduction rotary kiln is studied by the computational fluid dynamic approach. Based on the simulation results, the following conclusions can be drawn:

(1) A temperature gradient $(\Delta T)$ was found in the bed, which is maximal near the kiln tail and decreases gradually as the reduction process progresses.

(2) The reductions of $\mathrm{Fe}_{2} \mathrm{O}_{3}$ to $\mathrm{Fe}_{3} \mathrm{O}_{4}$ and $\mathrm{Fe}_{3} \mathrm{O}_{4}$ to $\mathrm{FeO}$ are always fast, and the reduction of $\mathrm{FeO}$ to $\mathrm{Fe}$ is the limiting step of the whole reduction process because this reaction requires a higher reduction potential. $\mathrm{H}_{2}$ makes little contribution to the reduction of $\mathrm{FeO}$ to $\mathrm{Fe}$, and $\mathrm{CO}$ is the major reducing agent for this reduction reaction.

(3) The reduction potential curves can be divided into three parts. The curves increase rapidly in the first part and then remain nearly constant in the second part. In the third part, the curves increase again until the products are discharged from the kiln head.

(4) The $\mathrm{C} / \mathrm{O}$ mole ratio has little effect on the average bed temperature but has a strong effect on the reduction potential. The higher reduction potential promoted the reduction process.

(5) With the increase of fill degree, both average bed temperature and reduction potential decrease. When the fill degree increases to $26.6 \%$, the final metallization rate is only $26.3 \%$.

Author Contributions: Conceptualization, C.L. and X.D.; methodology, X.Y.; software, C.L.; validation, H.L., C.D. and J.W.; formal analysis, C.L.; investigation, J.W.; resources, C.D.; data curation, H.L.; writing—original draft preparation, C.L.; writing—review and editing, X.D.; visualization, X.Y.; supervision, X.D.; project administration, X.Y.; funding acquisition, X.D. All authors have read and agreed to the published version of the manuscript.

Funding: This research was funded the National Key R\&D Program of China (2017YFB0603801).

Institutional Review Board Statement: Not applicable.

Informed Consent Statement: Not applicable.

Data Availability Statement: Not applicable.

Conflicts of Interest: The authors declare no conflict of interest.

\section{Nomenclature}

$\begin{array}{llll}A_{s} & \text { Area }\left(\mathrm{m}^{2}\right) & \mathrm{R} & \text { Molar gas constant }(\mathrm{J} / \mathrm{mol} \cdot \mathrm{K}) \\ C_{p} & \text { Specific heat capacity }(\mathrm{J} / \mathrm{kg} \cdot \mathrm{K}) & R_{i} & \text { Rate of reaction } i\left(\mathrm{~mol} / \mathrm{m}^{3} \cdot \mathrm{s}\right) \\ D_{i} & \text { Mass diffusion coefficient }\left(\mathrm{m}^{2} / \mathrm{s}\right) & R e & \text { Reynolds number }(-) \\ D_{s h} & \text { Diameter of kiln }(\mathrm{m}) & S_{\phi, p} & \text { Source term for phase } p\left(\mathrm{~kg} / \mathrm{m}^{3} \cdot \mathrm{s}\right) \\ E_{a, i} & \text { Activation energy of reaction } i(\mathrm{~J} / \mathrm{kg} \cdot \mathrm{mol}) & \mathrm{T} & \text { Temperature }(\mathrm{K}) \\ F_{g s} & \text { Drag force }\left(\mathrm{N} / \mathrm{m}^{2}\right) & v_{p} & \text { Velocity of phase } p(\mathrm{~m} / \mathrm{s}) \\ \mathrm{Gr} & \text { Grashof number }(-) & Y_{i} & \text { Mole fraction of species } i(-) \\ H_{p} & \text { Enthalpy of phase } p(\mathrm{~J} / \mathrm{mol}) & \text { Greek Symbols } \\ \Delta H_{i} & \text { Enthalpy of reaction } i(\mathrm{~J} / \mathrm{mol}) & \alpha_{s} & \text { Thermal diffusivity }\left(\mathrm{m}^{2} / \mathrm{s}\right) \\ h & \text { Heat transfer coefficient }\left(\mathrm{W} / \mathrm{m}^{2} \cdot \mathrm{K}\right) & \varepsilon_{p} & \text { Volume fraction of phase } p(-) \\ J & \text { Radiation intensity }\left(\mathrm{W} / \mathrm{m}^{2}\right) & \theta & \text { Central angel }(\mathrm{rad}) \\ k & \text { Turbulence kinetic energy }(\mathrm{J}) & \lambda_{p} & \text { Thermal conductivity }(\mathrm{W} / \mathrm{m} \cdot \mathrm{K}) \\ K_{e, i} & \text { Equilibrium constant of reaction } i(-) & \rho_{p} & \text { Density of phase } p\left(\mathrm{~kg} / \mathrm{m}^{3}\right) \\ M_{i} & \text { Molecular weight of species } i(\mathrm{~kg} / \mathrm{mol}) & \sigma & \text { Stefan-Boltzmann constant }\left(\mathrm{W} / \mathrm{m}^{2} \cdot \mathrm{K}^{4}\right) \\ P & \text { Pressure }(\text { Pa) } & \text { Subscripts } \\ P r & \text { Prandtl number }(-) & \mathrm{g} & \text { Gas phase } \\ q & \text { Heat flux }\left(\mathrm{J} / \mathrm{m}^{2} \cdot \mathrm{s}\right) & \mathrm{s} & \text { Solid phase }\end{array}$

\section{References}

1. Quader, M.A.; Ahmed, S.; Dawal, S.Z.; Nukman, Y. Present needs, recent progress and future trends of energy-efficient Ultra-Low Carbon Dioxide $\left(\mathrm{CO}_{2}\right)$ Steelmaking (ULCOS) program. Renew. Sustain. Energy Rev. 2016, 55, 537-549. [CrossRef] 
2. Xu, W.; Cao, W.; Zhu, T.; Li, Y.; Wan, B. Material Flow Analysis of $\mathrm{CO}_{2}$ Emissions from Blast Furnace and Basic Oxygen Furnace Steelmaking Systems in China. Steel Res. Int. 2015, 86, 1063. [CrossRef]

3. Qu, Y.; Yang, Y.; Zou, Y.; Zeilstra, C.; Meijer, K.; Boom, R. Thermal decomposition behavior of fine ore particle. ISIJ Int. 2014, 53, 2196-2205. [CrossRef]

4. Srivastava, B.; Roy, S.K.; Sen, P.K. An Approach for Simulation of COREX Process Smelter Gasifier for Prediction of Coal Rate and Silicon in Hot Metal. Metall. Mater. Trans. B 2010, 41, 935-939. [CrossRef]

5. Wu, S.; Xu, J.; Yang, S.; Zhou, Q.; Zhang, L. Basic Characteristics of the Shaft Furnace of COREX(R) Smelting Reduction Process Based on Iron Oxides Reduction Simulation. ISIJ Int. 2010, 50, 1032-1039. [CrossRef]

6. Liu, X.; Pan, G.; Wang, G.; Wen, Z. Mathematical model of lump coal falling in the freeboard zone of the COREX melter gasifier. Energy Fuels 2011, 25, 5729-5735. [CrossRef]

7. Zhang, X.H.; Zhao, K.; Bai, G.C.; Zhang, Y.Z.; Gao, J.J.; Zhang, Y.Y. Thermal analysis of rotary kiln oxygen combustion melting furnace under multi-constraint conditions. Iron Steel 2020, 55, 9-15.

8. Gao, J.J.; Wan, X.Y.; Qi, Y.H.; Wang, F. Technical analysis on ironmaking process of rotary kiln pre-reduction and smelting by coal and oxygen. J. Iron Steel Res. 2018, 30, 91-96.

9. Kingsley, T.C.; Kritzinger, H.P. Modelling and optimization of a rotary kiln direct reduction process. J. South. Afr. Inst. Min. Metall. 2015, 115, 51-60.

10. Mujumdar, K.S. Modeling of Rotary Cement Kilns: Applications to Reduction in Energy Consumption. Ind. Eng. Chem. Res. 2016, 45, 2315-2330. [CrossRef]

11. Mujumdar, K.S.; Ranade, V.V. CFD modeling of rotary cement kilns. Asia-Pac. J. Chem. Eng. 2008, 3, 106-118. [CrossRef]

12. Gaurav, G.K.; Khanam, S. Computational fluid dynamics analysis of sponge iron rotary kiln. Case Stud. Therm. Eng. 2016, 9, 14-27. [CrossRef]

13. Gaurav, G.K.; Khanam, S. Analysis of temperature profile and \% metallization in rotary kiln of sponge iron process through CFD. J. Taiwan Inst. Chem. Eng. 2016, 63, 473-481. [CrossRef]

14. Manju, M.S.; Savithri, S. Three dimensional CFD simulation of pneumatic coal injection in a direct reduction rotary kiln. Fuel 2012, 102, 54-64. [CrossRef]

15. Vicente, W.; Ochoa, S.; Aguillon, J.; Barrios, E. An Eulerian model for the simulation of an entrained flow coal gasifier. Appl. Therm. Eng. 2003, 23, 1993-2008. [CrossRef]

16. Merrick, D. Mathematical models of the thermal decomposition of coal. Fuel 1983, 62, 540-546. [CrossRef]

17. Kuwauchi, Y.; Barati, M. A Mathematical Model for Carbothermic Reduction of Dust-Carbon Composite Agglomerates. ISIJ Int. 2013, 53, 1097-1105. [CrossRef]

18. Donskoi, E.; Mcelwain, D.L.S.; Wibberley, L.J. Estimation and modeling of parameters for direct reduction in iron ore/coal composites: Part II. Kinetic parameters. Metall. Mater. Trans. B 2003, 34, 255-266. [CrossRef]

19. Magnussen, B.F.; Hjertager, B.H. On mathematical modeling of turbulent combustion with special emphasis on soot formation and combustion. Symp. Combust. 1977, 16, 719-729. [CrossRef]

20. Silaen, A.; Wang, T. Effect of turbulence and devolatilization models on coal gasification simulation in an entrained-flow gasifier. Int. J. Heat Mass Transf. 2010, 53, 2074-2091. [CrossRef]

21. Mei, Z.; Li, P.; Wang, F.; Zhang, J.; Mi, J. Influences of Reactant Injection Velocities on Moderate or Intense Low-Oxygen Dilution Coal Combustion. Energy Fuels 2013, 28, 369-384. [CrossRef]

22. Sun, S.; Lu, W.K. Mathematical Modeling of Reactions in Iron Ore/Coal Composites. ISIJ Int. 2007, 33, 1062-1069. [CrossRef]

23. Sun, S.; Lu, W.K. Building of a Mathematical Model for the Reduction of Iron Ore in Ore/Coal Composites. ISIJ Int. 2007, 39, 130-138. [CrossRef]

24. Sun, K.; Lu, W.K. Mathematical Modeling of the Kinetics of Carbothermic Reduction of Iron Oxides in Ore-Coal Composite Pellets. Metall. Mater. Trans. B 2009, 40, 91-103. [CrossRef]

25. Jones, W.P.; Launder, B.E. The prediction of laminarization with a two-equation model of turbulence. Int. J. Heat Mass Transf. 1972, 15, 301-314. [CrossRef]

26. Jaw, Y.; Chen, C. Fundamentals of turbulence modeling. J. Fluid Mech. 1998, 371, 379-381.

27. Chui, E.H.; Raithby, G.D. Computation of radiant heat transfer on a nonorthogonal mesh using the finite-volume method. Numer. Heat Transf. Part B Fundam. 1993, 23, 269-288. [CrossRef]

28. Smith, T.F.; Shen, Z.F.; Friedman, J.N. Evaluation of coefficients for the weighted sum of gray gases model. ASME J. Heat Transf. 1982, 104, 602-608. [CrossRef]

29. Gorog, J.P.; Adams, T.N.; Brimacombe, J.K. Regenerative heat transfer in rotary kilns. Metall. Trans. B 1982, 13, 153-163. [CrossRef]

30. Tscheng, S.H.; Watkinson, A.P. Convective heat transfer in a rotary kiln. Can. J. Chem. Eng. 1979, 57, 433-443. [CrossRef]

31. Marias, F.; Roustan, H.; Pichat, A. Modelling of a rotary kiln for the pyrolysis of aluminium waste. Chem. Eng. Sci. 2005, 60, 4609-4622. [CrossRef]

32. Boateng, A.A. On flow-induced kinetic diffusion and rotary kiln bed burden heat transport. Chem. Eng. Commun. 1998, 170, 51-66. [CrossRef]

33. Boateng, A.A.; Barr, P.V. A thermal model for the rotary kiln including heat transfer within the bed. Int. J. Heat Mass Transf. 1996, 39, 2131-2143. [CrossRef] 
34. Agrawal, A.; Ghoshdastidar, P.S. Numerical simulation of heat transfer during production of rutile titanium dioxide in a rotary kiln. Int. J. Heat Mass Transf. 2017, 106, 263-279. [CrossRef] 